Abstracta Iranica Abstracta Iranica

Revue bibliographique pour le domaine irano-aryen

Volume 40-41 | 2019

Comptes rendus des publications de 2017-2018

\title{
Madeleine Mumcuoglu, Yosef Garfinkel. Crossing the Threshold. Architecture, Iconography and the Sacred Entrance
}

\section{Astrid Nunn}

\section{(2) OpenEdition Journals}

Édition électronique

URL : http://journals.openedition.org/abstractairanica/49355

DOI : $10.4000 /$ abstractairanica. 49355

ISBN : 1961-960X

ISSN : 1961-960X

Éditeur :

CNRS (UMR 7528 Mondes iraniens et indiens), Éditions de l'IFRI

\section{Référence électronique}

Astrid Nunn, "Madeleine Mumcuoglu, Yosef Garfinkel. Crossing the Threshold. Architecture, Iconography and the Sacred Entrance », Abstracta Iranica [En ligne], Volume 40-41 | 2019, document 52, mis en ligne le 30 octobre 2019, consulté le 23 avril 2021. URL : http://journals.openedition.org/abstractairanica/ 49355 ; DOI : https://doi.org/10.4000/abstractairanica.49355

Ce document a été généré automatiquement le 23 avril 2021.

Tous droits réservés 


\title{
Madeleine Mumcuoglu, Yosef Garfinkel. Crossing the Threshold. Architecture, Iconography and the Sacred Entrance
}

\author{
Astrid Nunn
}

\section{RÉFÉRENCE}

Madeleine Mumcuoglu, Yosef Garfinkel. Crossing the Threshold. Architecture, Iconography and the Sacred Entrance. Oxford: Oxbow Books, 2018, 208 p.

1 Les AA. partent de la constatation que des millions d'humains passent quotidiennement un seuil, et que la plupart d'entre eux n'ont pas conscience de ce que signifie un seuil, que ces passages soient religieux ou profanes. De plus, stimulés par la découverte dans leur fouille de Khirbet Qeifaya d'un modèle et d'un autel du Fer II dont l'entrée et les côtés sont respectivement marqués par des redents, les A ont réfléchi sur les ouvertures à redents dans l'antiquité. Cet élément se retrouve sur des façades réelles de temples, de palais et de tombes aussi bien que sur des imitations de façades que l'on retrouve dans de nombreuses catégories d'objets: maquettes, stèles, ivoires. Avec étonnement ils constatent une continuité de l'époque d'Obeid (Vème millénaire) à l'époque moderne. Le secret de cette longévité réside certainement dans le fait que l'entrée des bâtiments importants doit être accentuée, et que les redents en sont un moyen simple.

2 La période achéménide se retrouve dans le "Chapter 8: Recessed Openings in First Millennium BCE Mesopotamia" (avec Persépolis) et dans le "Chapter 9: Recessed Openings in the Iron Age and Persian Period in the Levant, Sardinia and Carthage (10th to fourth centuries BCE)" avec les chapiteaux chypriotes et les stèles funéraires 
phéniciennes. Cette étude est intéressante malgré la disparité du matériel et la relative superficialité du texte.

\section{AUTEURS}

\section{ASTRID NUNN}

Université de Munich 